\title{
GEOGRAFIA ELECTORAL DE ANDALUCIA
}

Antonio J. Porras Nadales

En general, la dinámica electoral andaluza puede presentarse como un significativo precedente de la tendencia al auge socialista manifestada en 1982 en el conjunto del electorado español, con una especial peculiaridad, que esta tendencia se manifiesta entre un electorado básicamente rural, aunque sometido en las últimas décadas a importantes procesos migratorios que refuerzan el fenómeno de la concentración urbana y el despoblamiento rural. En 1982 la población urbana (municipios con más de 70.000 habitantes) representa ya un 38 por 100 del censo, mientras la población en municipios con menos de 5.000 habitantes desciende hasta cerca de un 15 por 100 .

Está claro que la evidente vocación izquierdista del electorado andaluz no puede interpretarse exclusivamente como el resultado de una polarización voto rural/voto urbano, aunque en algunas zonas se podría deducir de los datos de 1977: por el contrario, hay un voto rural socialista-comunista en todo el espacio de Campiña del gran Valle del Guadalquivir, en zonas de pueblos grandes y agricultura avanzada, que singulariza en su conjunto el resultado del mapa electoral de Andalucía.

En el presente trabajo hemos procesado los resultados electorales de las elecciones generales de 1977, 1979 y 1982 (básicamente, por razones de homogeneidad), con niveles municipales de renta per capita y población, y ordenación por comarcas provinciales y grandes comarcas regionales. 


\section{ANALISIS GEOGRAFICO}

La fijación de las grandes líneas geográficas del comportamiento electoral de Andalucía no puede desvincularse inicialmente del marco provincial: hay provincias con una clara dominancia relativa comunista, como Córdoba; una provincia singularmente andalucista, como Cádiz; el máximo voto conservador de Almería, etc. En general, el bloque de voto más acusadamente izquierdista se sitúa en el mismo cono sur de la Península: Sevilla, Córdoba, Cádiz; mientras las provincias con tendencias relativas más conservadoras, aunque con distinta dinámica, se sitúan en la periferia, especialmente en la zona oriental. A su vez, dentro de cada provincia, la evolución geográfica del voto tiende a seguir líneas de dispersión semejantes: un bloque de voto más progresista, con una mayor apertura pluralista, dinamicidad en las traslaciones y superior presencia de la izquierda alrededor de las capitales de provincia, que se irá dispensando centrífugamente hacia zonas rurales relativamente más conservadoras, con menor apertura pluralista, generalmente coincidentes con las comarcas serranas más alejadas de la capital.

\section{Las grandes comarcas}

Una superación geográfica del marco provincial puede realizarse en primer lugar en la habitual contraposición entre voto rural y urbano, o bien a través del diseño de grandes áreas comarcales andaluzas: nuestro gran mapa comarcal contiene tres grandes espacios a los que podemos atribuir comportamientos bien diferenciados.

La comarca de Sierra abarca el plegamiento de Sierra Morena al norte y las cordilleras béticas al sur. A efectos sociológicos consideramos las altiplanicies orientales de Granada y los espacios subdesérticos de Almería incluidos dentro de esta primera categoría. Se trata de las zonas rurales más atrasadas de Andalucía, con un quinto de la población total, predominio absoluto de unidades poblacionales mínimas y los más bajos niveles de renta, con altos índices de emigración en las últimas décadas. Políticamente, su comportamiento electoral se caracteriza por un reducido pluralismo con escasa elasticidad en los trasvases de votos y mayores tasas de abstención. En 1977 era una zona de dominio ucedista; en las máximas cotas de apertura pluralista de 1979 sigue siendo el espacio más estrictamente bipartidista con un 37,5 por 100 para cada uno de los dos grandes partidos, sin que ninguno de los partidos minoritarios restantes llegue a superar el 10 por 100 . Es, en todo caso, la zona con una menor presencia relativa de los partidos de la izquierda. Singularmente es, por fin, la única comarca regional donde el bloque centrista sigue manteniendo en el 82 una posición significativa, próxima al 10 por 100 .

La segunda gran comarca, la Campiña, se extiende por todo el eje central 
de Andalucía, siguiendo la depresión del Guadalquivir desde Jaén hasta Cádiz, con su prolongación al oeste hacia el Condado (en Huelva), al sur hacia Antequera (Málaga) y Granada, por la vega del Genil. Constituye una zona rural bien dotada de recursos agrarios, aunque no siempre bien repartidos, predominio de unidades poblacionales medianas o grandes, y niveles de renta intermedios; es además la comarca más poblada, superando el 30 por 100 del censo. Se trata del espacio con máxima incidencia del bloque de izquier$\mathrm{da}$, en especial debido a la fuerte posición del voto comunista que, incluso en la gran caída del 82, se mantiene en niveles próximos al 10 por 100 . Constituye el eje espacial que singulariza el conjunto del mapa andaluz por la fuerte incidencia de un proletariado rural militante de clara tendencia izquierdista: en 1982 el bloque de izquierda se aproxima al 73 por 100 de los votos emitidos.

Finalmente, la tercera gran comarca se extendería por la franja costera, aunque su máxima significación política se denota en las provincias de Cádiz y Málaga: municipios medianos o grandes, con mejores variables socioeconómicas, fuerte incidencia del sector terciario y en general un comportamiento electoral más pluralista, similar al espectro de las capitales de provincia; agrupa a un 20 por 100 del censo. Fue en 1979 uno de los espacios de máxima penetración del voto andalucista del PSA, especialmente en la zona occidental. Se diferencia en todo caso del espectro de comportamiento del voto urbano en la menor presencia comunista (inexistencia de un proletariado urbano) y derechista; es decir, hay una mayor uniformidad en el predominio de capas sociales y niveles de renta intermedios.

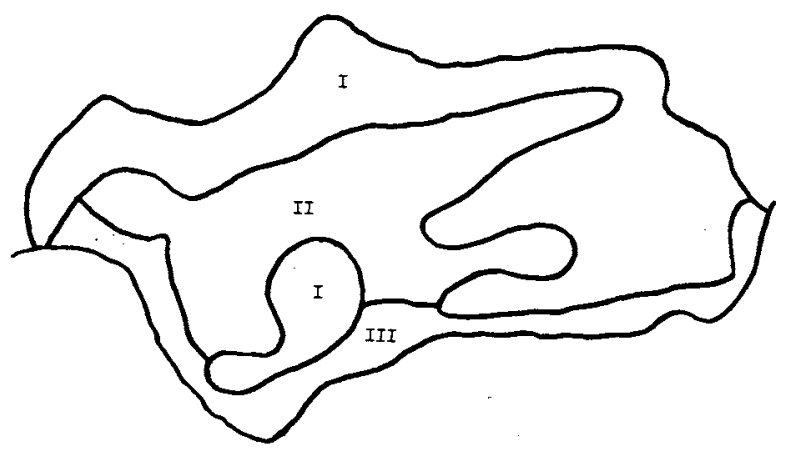

Grandes comarcas de Andalucla:

I. SIERRA.

II. CAMPIAA.

III. COSTA. 


\section{Las variaciones provinciales}

Esta ordenación de la dinámica electoral comarcal influye lógicamente en las distintas posiciones provinciales y permite, con ciertas matizaciones, defender una ordenación centro-periférica del comportamiento electoral. El centro, de máxima inflexión socialista-comunista, se situaría en el espacio intermedio de las cuatro provincias centrales, especialmente en la conocida bolsa «comunista» de la campiña cordobesa; mientras hacia la periferia (sobre todo en la zona oriental) el comportamiento político se caracteriza por la menor dinamicidad pluralista y una moderación en las opciones políticas.

Sin embargo, las cuatro provincias izquierdistas, Córdoba-Sevilla y CádizMálaga, tienen una dinámica diferenciada, condicionada por la peculiaridad del voto de campiña en las dos primeras y por el voto típico de costa en las segundas.

La dominancia comunista es más constatable en Córdoba y Sevilla desde 1977, con posiciones próximas al 15 por 100 , subiendo de dos a tres puntos en el 79. El voto típico de campiña se caracteriza también por la mayor incidencia del electorado de derecha conservadora de AP: incluso en las más bajas cotas de 1979, AP — voto vinculado a la burguesía rural conservadora - supera en Córdoba y Sevilla en dos puntos las posiciones relativas de Cádiz y Málaga. En cambio, estas dos últimas provincias presentan una estructura social claramente diferenciada, en ambas los niveles de población con más de 40.000 habitantes representan más del 60 por 100 del censo; salvo en las zonas serranas del interior, escasamente pobladas, son las provincias con superiores niveles de renta per capita de toda Andalucía. Esta peculiaridad se traducirá en una mayor oscilación hacia un bloque de centroizquierda-nacionalista. Es una oscilación perfectamente constatada en el paso de los datos del 77 al 79: mientras en Córdoba y Sevilla UCD desciende dos y cinco puntos, en Cádiz y Málaga hay una subida de unos dos puntos, y ello a pesar del apogeo andalucista que en Cádiz se aproxima al 20 por 100 . $\mathrm{La}$ incidencia del voto urbano o costero se caracteriza por la estabilidad global del voto centro-derecha en el marco del conocido trasvase UCD-AP, y siempre en términos absolutos: es paradigmática la posición del bloque UCD-AP en Cádiz, donde obtiene

$$
\begin{aligned}
& 134.000 \text { votos en } 1977 \\
& 135.000 » \gg 1979 \\
& 134.500 \gg \quad 1982
\end{aligned}
$$

Ciertamente las distintas tendencias del voto de campiña en CórdobaSevilla y el voto de costa en Cádiz-Málaga deben ser corregidas con algunas matizaciones, especialmente por la incidencia del voto urbano en Sevilla, donde el electorado en el nivel poblacional superior supone un 45 por 100 sobre el censo: su consecuencia es un mayor dinamismo en las traslaciones 
globales con resultados normalmente más pluralistas: Sevilla es la provincia con máxima pérdida del PSOE en 1979 (alcanzando su peor posición en toda Andalucía, ligeramente por encima del 25 por 100), caída directamente conectada al auge andalucista, que sube casi diez puntos, con una progresión en términos absolutos superior a la de Cádiz. Mientras en Córdoba, la menor incidencia del voto urbano e interclasista parece demostrarse por una mayor estabilidad relativa del electorado derecha de AP vinculado a burguesías rurales más conservadoras.

En cambio, la oscilación en el bloque centro-derecha mantiene las diferencias sustanciales, especialmente constatables en 1982, con una distinta dinámica en Cádiz y Málaga, donde el bloque de derecha aumenta más de 12.000 votos (aunque disminuyendo su posición relativa) mientras en Córdoba y Sevilla se pierden en el $82,6.000$ y 15.000 votos, respectivamente, para el bloque de derecha en relación con el 79. La diferencia señala claramente la doble polarización del voto derecha en costa y campiña: en Sevilla y Córdoba el declive centro-derechista va acompañado del máximo avance relativo, dentro del bloque, del electorado derecha-derecha, lo que debe conectarse con la mayor significación de un electorado rural vinculado a las burguesías agrarias; esto determinaría probablemente un sentido más arcaizante y conservador del voto de AP en estas provincias y, como reacción lógica, la mayor transfusión de votos centristas hacia la izquierda. En cambio, en Cádiz y Málaga puede hablarse tendencialmente de un voto más de derecha «civilizada» urbana, con menor trasvase de votos centristas hacia el PSOE.

Por su parte, Jaén se comporta como típica provincia rural de la semiperiferia oriental andaluza, donde aparecen perfectamente constatadas las diferencias de comportamiento entre la zona occidental de la provincia, con auge socialista-comunista propio de Campiña, frente al reborde serrano suroriental, próximo a los espacios orientales de Granada y Almería. Sin embargo, la relativa lejanía del eje occidental, de máxima presencia de la izquierda, tiene una clara expresión en el debilitamiento relativo del voto comunista, y, en consecuencia, la mejor posición del PSOE: en el 77 este partido obtiene aquí su segundo porcentaje después de Málaga, pero en 1979, el año de máxima expansión comunista, Jaén va a ser la máxima provincia socialista de toda Andalucía.

En todo caso su posición relativamente equilibrada, como provincia rural semiperiférica, se traduce en una mayor estabilidad del espectro total: estabilidad en el voto comunista (unos 30.000 electores), lo que hace que de ser en el 77 una de los provincias menos comunistas, se convierta en el 82 en la segunda provincia comunista tras Córdoba; estabilidad del voto centrista, que encuentra en el 82 en Jaén su segunda mejor posición (un 9 por 100) tras Almería. Estabilidad incluso en los ritmos de oscilación en las secuencias 1979 y 1982: el bloque de derecha pierde cinco puntos en cada una de las convocatorias, y el bloque de izquierda gana siete puntos en cada una. 
Huelva y Granada, al este y oeste del bloque central de la izquierda andaluza, presentan, con peculiaridades propias, una dinámica de traslación semejante: son en el 77 sólidos bloques del voto centrista, con posiciones próximas al 45 por 100 , y gran debilidad del voto socialista, dominando en términos absolutos el bloque de centro-derecha. Dos años más tarde el bloque total de la izquierda ha invertido posiciones. En términos absolutos:

Ventaja derecha 1977 Ventaja izquierda 1979

Votos

Granada $\ldots \ldots \ldots \ldots$

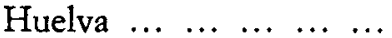

19.000

22.000
Votos

La oscilación, teniendo en cuenta que ninguna de las dos provincias se sitúa en los ejes de máxima expansión comunista (Valle del Guadalquivir) o andalucista (triángulo Cádiz, Sevilla, Málaga) ejemplifica claramente las líneas de oscilación general de la geografía electoral de Andalucía: la expansión del voto rural socialista en los sectores intermedios de los niveles de población y renta, y la penetración del voto urbano andalucista, que en 1982 se trasladará en bloque al PSOE. En ambas, por fin, hay un mantenimiento relativo del voto UCD (del 7 al 8 por 100) en las zonas más pobres de población serrana; mantenimiento que es más coherente, por cierto, en la atrasada y atomizada estructura municipal del este granadino, creando un espacio homogéneo de la Andalucía oriental con tasas similares de Jaén y Almería.

Estos tres procesos: progresión rural socialista en sectores intermedios, avance urbano andalucista y mantenimiento del voto centrista de sierra, explican en bloque la significación de los resultados de 1982 cuando el PSOE acumule votos a derecha e izquierda (urbano UCD/PSA y comunista de campiña), mientras AP no va a ser capaz de progresar en los sectores rurales de sierra, manteniendo curvas de voto típicamente urbanas.

Finalmente, Almería, la provincia más oriental, es el enclave más atrasado socialmente y de un sentido más conservador del conjunto del mapa andaluz. Es la única provincia donde el nivel municipal de menos de 5.000 habitantes representa la máxima posición sobre el censo provincial, próxima al 35 por 100, y donde los niveles más bajos de renta (menos de 70.000 pesetas de renta per capita) suponen casi un 40 por 100 del censo. Su comportamiento inicial en el 77 se caracteriza por el voto masivo de centro, especialmente en la zona subdesértica interior, con una presencia socialista constatable tan sólo en los municipios costeros. El avance rural socialista en el 79 no evita la victoria del bloque de derecha, con un espectro escasamente pluralista, 
acumulando los dos primeros partidos más del 80 por 100 de los votos. En el 82 las comarcas interiores más subdesarrolladas presentarán incluso cotas de un 15 ó un 20 por 100 de UCD.

\section{ANALISIS ESTRUCTURAL}

Basamos nuestro estudio en la indexación municipal por niveles de renta y población de toda Andalucía, determinando la posición relativa de cada partido en las series sucesivas de 1977, 1979 y 1982 a los distintos niveles. El principal inconveniente metodológico de este sistema radica en que el grado de diferenciación y clarificación de las curvas suele ser inversamente proporcional al grado de concentración del voto en uno o pocos partidos: de ahí que, al menos inicialmente, el marco más idóneo para determinar la peculiaridad estructural de cada partido sea el estudio de los resultados de 1979 , donde la amplitud pluralista del espectro político alcanza una mayor apertura, interpretando así los datos del 82 como el resultado de un proceso cuantificable de trasvase de votos a favor del PSOE y de la derechista CD.

\section{Los grandes bloques derecha/izquerda}

Inicialmente, separando el electorado andaluz en los grandes bloques derecha e izquierda, la máxima dominancia respectiva sirve como punto de guía a nuestro estudio: el bloque de la izquierda tiene su máximo asentamiento en municipios medianos, entre 15.000 y 70.000 habitantes; niveles poblacionales que representan aproximadamente una cuarta parte del electorado andaluz, y donde el bloque de izquierda llega casi a duplicar a la derecha: la posición media sería de un 33 por 100 para la derecha y un 63 por 100 para el bloque de izquierda. Económicamente este espacio electoral se corresponde con los sectores medios de renta municipal, y su localización geográfica abarcaría prioritariamente al gran bloque de la Campiña, la zona agraria más rica, con mayor concentración poblacional del electorado rural.

Por su parte, la máxima agudización del bloque de derecha se centra en 1979, siguiendo la inercia de la consulta anterior, en los núcleos urbanos menores de 5.000 habitantes y especialmente en los más ínfimos niveles de renta; o sea, zonas atrasadas y sectores subdesarrollados que geográficamente debemos localizar en los espacios de la Sierra. Un electorado que supone en total un quinto del censo andaluz. Bien entendido que esta máxima posición se enmarca en un contexto de predominio absoluto del bloque de izquierda en toda Andalucía, y que esta base social parece constituir un soporte poco estable para el bloque de derecha: los datos de 1982 demuestran que este nivel fue en las consultas anteriores el foco de apoyo no a la «derecha» abstractamente considerada, sino más bien al partido gubernamen- 
tal; la dificultad de avance de la derecha de Alianza Popular en este medio rural supone un importante giro que hace disminuir la presencia del bloque de derecha en este medio social.

Por último, los sectores del electorado típicamente urbano presentan una situación intermedia entre los dos polos anteriores, salvando de nuevo la victoria global de la izquierda. Interesa, en primer lugar, destacar la presencia más estable de este electorado urbano de un sector de derecha pura, perceptible incluso en los peores momentos de Alianza Popular en 1979: probablemente el sustrato más firme del bloque social franquista, que se confirma palpablemente por las superiores tasas del sexto partido a la derecha, Fuerza Nueva. Es más que significativo que en el año 82, cuando el voto rural por el hundimiento del Centro deja de prestar su apoyo al centroderecha sea en este sector donde se produce ahora la mayor presencia relativa del bloque de derecha, con alrededor de un 30 por 100: los mayores índices de renta y de población urbana.

Además, la peculiaridad ideológica de las capas medias urbanas va a generar, a través del gancho andalucista y su indudable éxito de 1979, un fenómeno de acercamiento hacia el bloque de izquierda: el PSA parece efectivamente haber actuado como oferta de atracción hacia sectores medianamente progresistas, aunque indecisos, del electorado andaluz. Dentro de ese bloque progresista de media clase urbana parece haber operado finalmente la dinámica del voto útil ( $\mathrm{y}$ las incoherencias del propio partido andalucista) a favor del PSOE, en las generales de 1982.

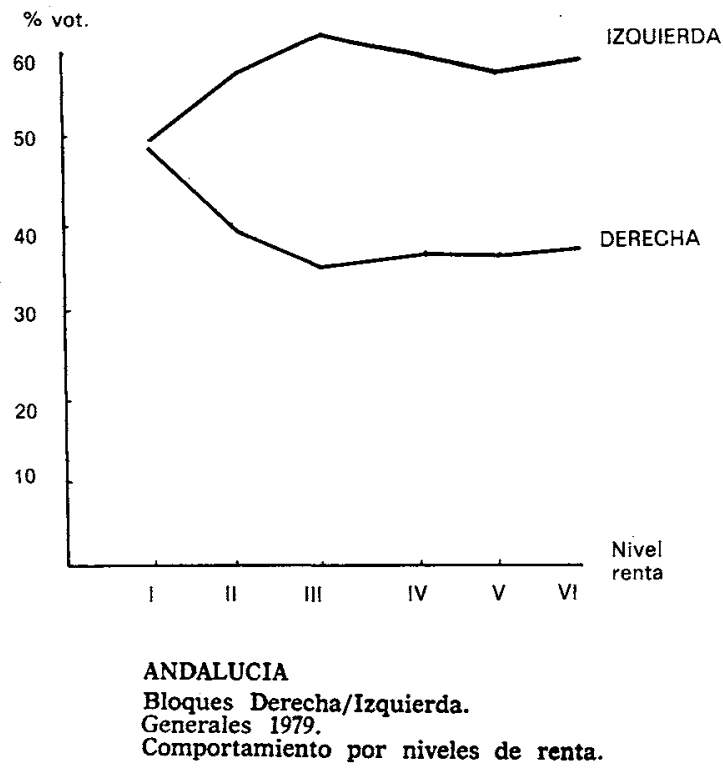




\section{El electorado comunista}

El electorado del Partido Comunista constituye la expresión más característica de la opción izquierdista de un sector de los trabajadores andaluces. En la determinación de su perfil sociológico influyen al menos tres variables distribuidas desigualmente:

I. Su espectro más significativo parece ser un sector de población trabajadora rural, asentada predominantemente en municipios medianos (superiores siempre a los 5.000 habitantes), en zonas agrarias relativamente ricas (Córdoba, Sevilla, Jaén, Granada), sector poblacional en que este partido tiene más de un 15 por 100 del electorado en las cotas más «transparentes» de 1979. Insistamos en la calificación de zonas relativamente «ricas»: en la tabulación por niveles de renta el PC presenta una curva ascendente salvo en los excepcionales casos de los niveles de renta 6 , de cierta significación sólo en la costa malagueña. En el cataclismo del 82 será éste el único sector donde se mantiene una cierta fidelidad comunista del típico voto de campiña, cifrable en un 10 por 100 .

II. Su segundo sector estaría integrado por el electorado asalariado urbano de poblaciones mayores; debe destacarse que no cabe hablar aquí en rigor de proletariado industrial «stricto sensu», o al menos como fenómeno generalizado. Población asalariada que puede tener especial relevancia en el inflacionado sector terciario de la economía andaluza (especialmente en Málaga) o en sectores del comercio agrario jerezano, así como dispersamente en las principales ciudades-cabeceras de comarca.

Es posiblemente el sector social más débil o inestable del electorado comunista y su distribución geográfica es también irregular. Potencialmente, señalará el máximo porcentaje de traslación posible hacia el voto socialista, de ahí que tenga cierta incidencia en provincias donde priman los niveles poblacionales medios.

Que se trata probablemente del sector más débil del electorado socialista es algo que demostrarán los datos de 1982. Es especialmente significativa la variación de las curvas en Málaga, donde, en 1979, el PC tenía un doble sector de máxima dominancia relativa con tasas superiores al 10 por 100 : el del voto rural de municipios menores de 15.000 habitantes, y el de sectores poblacionales medios no industrializados, en poblaciones con más de 40.000 habitantes; en 1982 únicamente en el primer nivel de voto más típicamente rural conservará el PC ciertas posiciones, descendiendo en el otro sector muy por debajo del 5 por 100 .

III. Finalmente, aparecería, fundamentalmente en la periferia de la capital sevillana, el típico electorado comunista industrial vinculado a una sólida sindicación; sólo parcialmente subsiste este tipo de electorado en otras capitales de provincia, por ejemplo en Huelva, donde va a demostrar una escasa estabilidad con una rotunda caída en el 82 de más de 10 puntos. 
Como electorado típicamente urbano, su significación será mayor en los distritos periféricos urbanos de la capital sevillana, distritos de Cerro del Aguila, Torreblanca y San Jerónimo.

La mayor originalidad del comportamiento del electorado comunista reside, en nuestra opinión, en su inexorable conexión con cotas relativamente altas de los niveles de renta; o sea, nivel poblacional rural típico de campiña, y nivel intermedio $(2$ y 3 ) de renta per capita. La confirmación del fenómeno viene a echar por tierra el viejo mito de los movimientos campesinos andaluces como fenómenos milenaristas vinculados a la miseria material más absoluta. Provisionalmente podemos afirmar que es esta variable, el nivel de renta, la que más decisivamente determina la posición del $\mathrm{PC}$, y no probablemente los índices de distribución de propiedad que, hasta donde hemos podido inducir, se comportan con gran irregularidad.

¿Dónde ubicamos, pues, el subproletariado campesino de las zonas marginadas más pobres? Si estableciéramos dos modelos paradigmáticos alternativos podría afirmarse que:

A) En las zonas de la periferia andaluza, especialmente en las comarcas subdesérticas orientales, este sector marginal permanece en gran medida en lo que, en términos marxistas, podríamos considerar como etapas anteriores a la conciencia de clase: constituye probablemente el bloque central del electorado de la incultura y el subdesarrollo, que siguió la inercia del «voto al sistema» en 1977, con exorbitantes cotas de UCD y escaso o nulo pluralismo político. La evolución, en su más provisional constatación, parece apuntar hacia el bloque del voto «seguro» del PSOE, probablemente a través de cauces escasamente racionalizables.

B) Por el contrario, el voto de este subproletariado agrario en las zonas del «centro» izquierdista andaluz, especialmente en el centro del cuadrángulo Cádiz, Málaga, Córdoba y Sevilla, se traduce en comportamientos claramente más extremistas, seguramente más próximos en su origen a la tradición violenta del campesinado andaluz de otros tiempos. Su resultado serán posiciones constatables para el Partido del Trabajo, beneficiario del gancho de SOC en la zona de sierra sur de Sevilla y sierra de Cádiz. También este electorado pasará en el 82 a engrosar el flujo centrípeto del PSOE.

Geográficamente, este electorado comunista se asienta primordialmente en las zonas más ricas de Andalucia: su centro focal estaría en la campiña cordobesa, desde donde evoluciona hacia el oeste a Sevilla, al este a Jaén y al sur poì la comarca de Antequera hacia Granada y la costa. Las mínimas posiciones comunistas deben buscarse, en cambio, en la periferia serrana, sobre todo en los polos occidental y oriental de la región: Sierra y Andévalo occidental de Huelva, sierras de Huéscar, Guadix y Baza en Granada y toda la zona interior de Almería. 


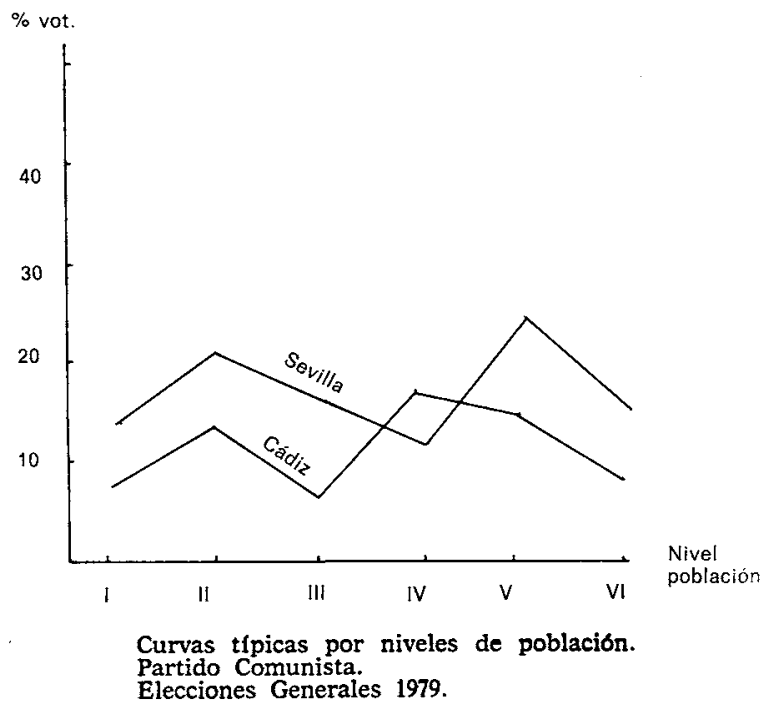

$\%$ vot.

$\%$ vot.

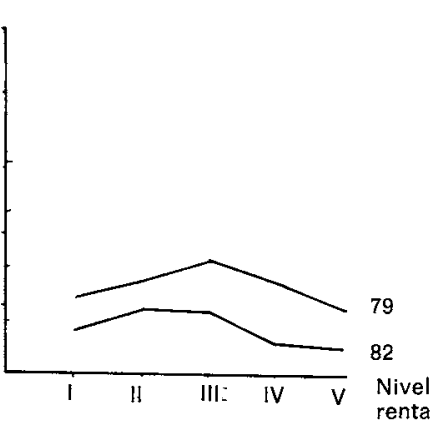

GRANADA

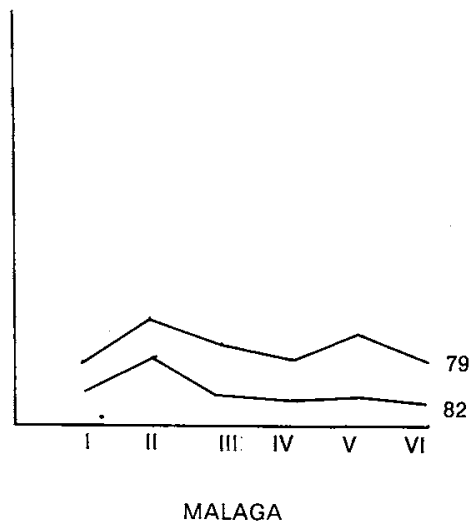

Elecciones 1979, 1982.

Curvas por niveles de renta.

Partido Comunista.

\section{El electorado andalucista}

En cuanto al partido andalucista, la naturaleza de su espectro electoral podría definirse rotundamente como electorado predominantemente urbano, base social que tiende lógicamente a concentrarse en los niveles poblacionales de rentas altas.

$\mathrm{Su}$ asentamiento y desarrollo tiene, sin embargo, una gran desigualdad geográfica: el voto nacionalista aparece como un fenómeno característico de la Andalucía occidental. Su punto álgido se sitúa en el eje Cádiz-Jerez, 
a partir del cual la ola andalucista se dispersa en círculos concéntricos, perdiendo progresivamente intensidad hasta las mínimas cotas de Jaén y Almería.

Dentro de su espacio geográfico, pues, el votante andalucista debe encuadrarse entre sectores de las clases medias. Ideológicamente constituirá un sector moderadamente progresista, aunque de una escasa definición ante la «cuestión social»: lo cual nos permitiría excluir posiblemente a amplias capas de la población asalariada en sentido estricto (trabajadores manuales), tesis que podríamos confirmar por la inexistencia de una base sindical que sirva de soporte al partido andalucista; de hecho, los intentos de captar al Sindicato de Obreros del Campo a través de pactos con el PT y a pesar de manifestaciones de personalidades tan prestigiosas como Francisco Casero, han demostrado haber terminado en un fracaso, por lo que a su resultado electoral se refiere.

Así pues, la hipótesis de las burguesías periféricas como modelo de interpretación del fenómeno nacionalista en España debería ser sustituido en Andalucía por el soporte social de la pequeña burguesía periférica.

Estructuralmente, se trata de un electorado poco estable, probablemente sensible a campañas agresivas de imagen nueva; ideológicamente condicionado por el dilema de la opción socialdemócrata y la escasa concreción del soporte ideológico del «nacionalismo dependiente». Curiosamente, esta relativa inconsistencia de la base electoral andalucista parece generar diferencias provinciales bastante notables en su dinámica: salvando todas las precauciones, podría afirmarse con alguna certeza que en las provincias del «centro» andalucista, Cádiz, Sevilla y Málaga, el auge del PSA del 79 se basa primordialmente en su detracción de electorado de izquierda; mientras en las provincias más periféricas de Córdoba y Granada detrae electorado más típicamente de centro, fenómeno que en parte se reproduce en Huelva.

Tan ambigua contradicción no es más que un reflejo de la propia ambigüedad del nacionalismo andaluz: un mayor radicalismo verbal y una mayor presión en la oferta política en las provincias del «centro» andalucista tiende a generar una aproximación lógica hacia las posiciones de una emergente extrema izquierda ultranacionalista, fomentada por diversos medios culturales y políticos, y, en consecuencia, encuentra una aceptación inicial entre ciertas capas campesinas.

Por el contrario, en el marco de una clase media más rural en cuanto a sus sistemas de pensamiento, de las provincias de Huelva, Córdoba o Granada, el progresismo andalucista operaría como una oferta avanzada, aunque ideológicamente no comprometida, adecuada para encauzar un moderado avance de un electorado anteriormente de centro.

La caída de posiciones del electorado andalucista en el 82 no debe interpretarse, sin embargo, como un irreversible fracaso de la misión política del PSA. Con independencia del rotundo éxito del PSOE para asumir y atraerse la romántica expectativa del andalucismo, puede decirse que el PSA ha cum- 
plido una importante misión histórica en la evolución del sistema demográfico andaluz: ha sido, efectivamente, un elemento dinamizador de la conciencia política de importantes sectores de la población andaluza hacia posiciones progresistas e ideológicamente avanzadas; fenómeno que ha venido a traducirse en la coyuntura histórica de 1982 en un apoyo masivo hacia la izquierda, con verdadera perspectiva de mayoría a nivel nacional.

\% vot.

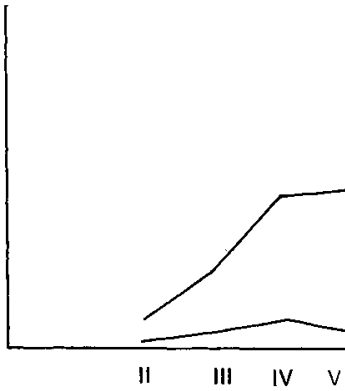

CADIZ

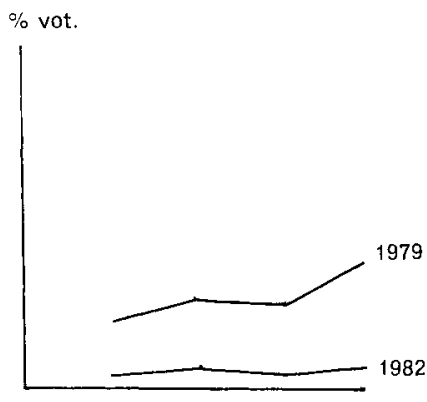

SEVILLA

PSA.

Curvas por niveles de renta.

$\%$ vot.

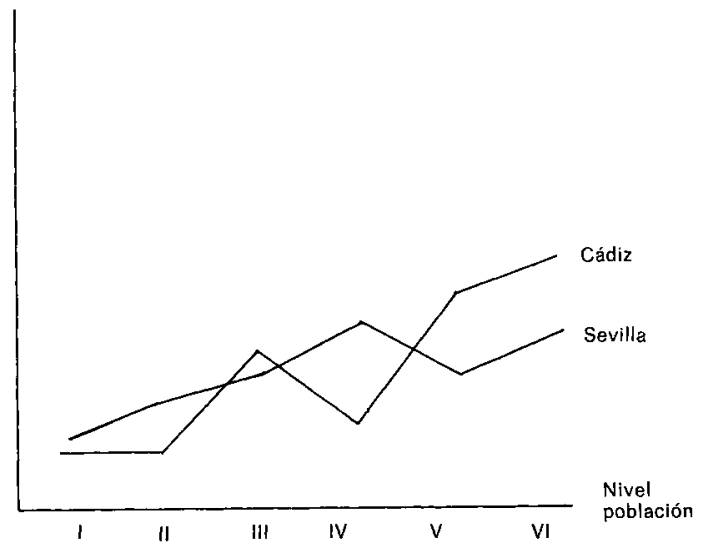

Partido Socialista de Andalucía (PSA).

Comportamiento por niveles de población.

Elecciones Generales 1979.

El voto socialista. PSOE

Prescindiendo en principio de la peculiaridad del voto urbano, más pluralista, en las ciudades mayores y capitales de provincia, la evolución del PSOE a distintos niveles de población tiende a ser distinta según nos encontremos 
ante provincias «de izquierda» o provincias «de derecha» (en términos relativos, claro está). En las primeras, la dominancia socialista se produce en los niveles más bajos de población, para seguir una curva descendente en niveles superiores; en cambio, en las provincias de derecha, las más pobres, dada la dominancia rural del voto conservador a UCD, el PSOE presenta una curva ascendente, que alcanza sus mayores cotas en los niveles medios de población, en municipios entre 15.000 y 25.000 habitantes. De ahí que la mayor estabilidad socialista se produzca en una provincia «media», Jaén.

Esta dominancia socialista en el espectro medio del electorado tiene su lógica traducción en la estructura comarcal del conjunto regional. El PSOE tiene sus mejores posiciones relativas en las comarcas de campiña, donde el predominio de los niveles poblacionales intermedios es más rotundo; al. contrario que UCD, que recogerá mejores posiciones en la sierra (con niveles mínimos de población) y entre el electorado urbano (consecuencia de la dispersión del voto de izquierda), donde UCD tendrá sus peores pérdidas en el 82 .

Habría, pues, un nivel máximo del electorado «natural» del PSOE que se situaría justo en los niveles intermedios de las variables indexadas. En definitiva, esto nos refleja la existencia de un bloque medio de clientela interclasista, como se corresponde con un partido de masas perfectamente asentado en todos los niveles municipales cuantificados.

La tendencia al descenso relativo de la curva socialista conforme aumentan los niveles de renta y población, es decir, conforme nos aproximamos al electorado urbano y a las zonas más ricas, no puede, sin embargo, interpretarse como una disminución de la posición de la izquierda, sino estrictamente como una diversificación en la pluralidad de opciones que canalizan el voto más progresista de la izquierda.

En el 82 el perfil de las curvas del PSOE será idéntico, aunque obviamente con unos mayores valores absolutos. La curva del PSOE es, sobre todo, más parecida a la que presenta el bloque de la izquierda por niveles de renta: la renta, como variable fundamental, determina las mayores posiciones del bloque de izquierda en los niveles medios, 3 y 4: especialmente en el nivel 3, que supone en el 79 un 62 por 100 del electorado de izquierda, lo que representa más de una quinta parte del electorado andaluz, concidente con el máximo nivel del PSOE.

La inflexión más significativa es la que (tanto en las generales del 79 como en las del 82) se produce en el nivel de renta 5, en parte coincidente con la caída en el nivel máximo de población (más de 70.000 habitantes). Nos encontramos aquí en el más destacado ejemplo de voto urbano y buena situación social y de equipamiento. En ambos casos bajos niveles relativos del PSOE y del bloque de izquierda (que, por supuesto, sigue siendo mayoritario). En el 79 esta mayor apertura pluralista se expresa en

- altos niveles del PC (sobre un 12 por 100); 
- máximo nivel del PSA (un 16 por 100);

- máximo nivel de la derecha pura (un 6,5 por 100);

- mínimo nivel de UCD (sobre el 28 por 100).

La dinámica urbana supone, pues, estructuralmente una inevitable tendencia polarizadora que perjudica a los partidos centrales mayoritarios: coincide justamente con la presencia de grupos asalariados industriales (PC), minorías dominantes social y económicamente (AP) y capas medias progresivas (PSA).

En el 82 el pluralismo se reduce al máximo, quedando una opción unipartidista con el 61 por 100 para PSOE y el 24 por 100 para Alianza Popular.

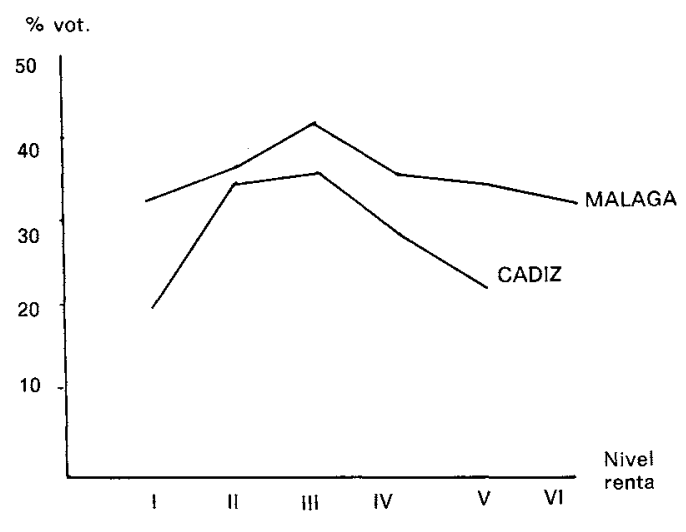

Curvas tipicas del PSOE.

Comportamiento por niveles de renta.

Elecciones Generales 1979.

\section{El electorado de centro}

Por lo que respecta al electorado de centro, el análisis es lógicamente más complejo: inicialmente porque en las convocatorias electorales de los años 77 y 79, la oferta de centro aparece de hecho concentrada a través de la oferta del voto útil al bloque de la derecha, y, por lo que respecta al 82 , porque la existencia de una oferta dividida y relativamente débil de centro, coincide con una gran atracción de la opción socialdemócrata a favor del PSOE. Geográficamente, la posición dominante del centro es claramente periférica y sobre todo oriental; es decir, perfectamente coincidente con los espacios menos desarrollados de Andalucía; la mayor acumulación geográfica se produce en las provincias de Huelva, Granada y Almería.

Estructuralmente, la curva que describe el electorado de centro-derecha (con la excepción de Huelva) tiene un perfil absolutamente inverso a la del electorado socialista. Es decir, máximos niveles en los indices más bajos de 
renta y población; inflexión descendente hasta el punto más bajo en los niveles intermedios, para alcanzar una cierta recuperación en las tasas mayores. En todo caso la curva en general tiene un sentido descendente que viene a coincidir no sólo con el avance de la izquierda, sino, simultáneamente, con la mayor apertura pluralista del electorado. El mínimo nivel del voto de centro en las primeras convocatorias coincide justamente con el máximo del PSOE.

Así pues, el bloque social predominante de este inicial sector mayoritario del centro-derecha presenta una composición heterogénea: composición que se corresponde precisamente con los sectores más extremos del electorado rural y del electorado urbano (y/o de costa), de los más bajos y los más elevados niveles de renta; semejante dinámica tiene su mejor traducción a nivel comarcal, donde se produce la paradójica situación de que la posición centrista resulta mayoritaria justamente en las comarcas «extremas», la sierra y la costa, donde coinciden el máximo nivel de subdesarrollo rural con el máximo nivel de «middle class» urbana.

Tal heterogeneidad es muestra evidente de una gran debilidad estructural y de integración del inicialmente mayoritario electorado de centro: en todo caso exige una difícil superposición de una oferta política populista y simultáneamente derechista que se articule en un eje de equilibrio a través de un cierto mensaje socialdemócrata o reformista.

Tal constatación no es más que una manifestación más del fenómeno -demostrado por Sartori- de la tendencia característica del pluralismo polarizado al debilitamiento del centro a través de una pérdida persistente de votos en favor de uno de los extremos o incluso de ambos. Resulta paradigmático que la experiencia española haya venido a confirmar de forma tan rotunda uno de los principales postulados de la moderna ciencia política de sistemas de partidos.

En todo caso estos datos vienen a demostrar una cierta inconsistencia estructural del necesario vínculo entre base social y oferta política partidista: la beterogeneidad de la base social sólo puede permitir una respuesta política unificada a base de acentuar el factor político del nexo electoral. Factor político que debería depender de una adecuada instrumentación de diversos elementos: alta intensidad de la campaña (con grandes desembolsos financieros); alto grado de liderazgo, y - si es posible- control de elementos políticos extraelectorales, es decir, de circuitos efectivos de poder central o local.

\section{El voto derecbista. AP}

La evolución de las curvas del electorado de AP sigue un perfil perfectamente similar a las del característico voto urbano andalucista: es decir, una clara progresión conforme aumentan los niveles de renta y población. Como es lógico, la determinación exacta de su electorado presenta la dificultad ini- 


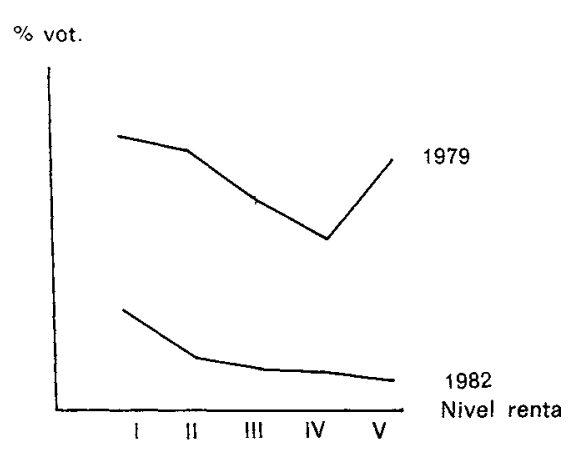

GRANADA
$\%$ vot.

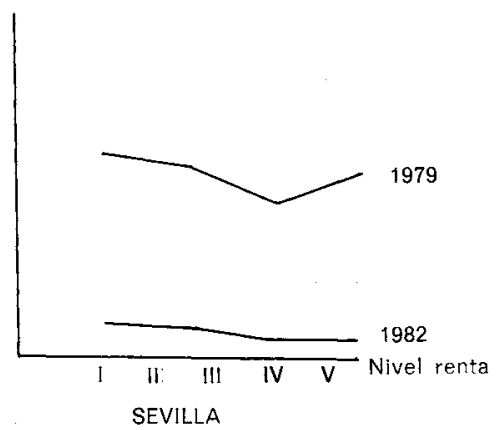

Curvas tipicas de UCD.

Comportamiento por niveles de renta.

cial de su confusión en las convocatorias del 77 y el 79 en el bloque ucedista: sin embargo, en el análisis provincial de los datos del 82 vienen a confirmarse rotundamente las tendencias anteriormente constatadas, es decir, el aumento más que proporcional del voto AP en las zonas más urbanizadas y de mayores niveles de renta: si en los sectores menos poblados y socialmente atrasados el aumento es de unos quince puntos, en las capitales y espacios más desarrollados este aumento es de unos 20 puntos.

Tal constatación permite, pues, aventurar de forma escasamente problemática la consecuente hipótesis: la base social natural del electorado de derecha debe buscarse prioritariamente entre sectores propietarios y de altos niveles de renta inicialmente vinculados al mundo rural y que sólo consiguen una cierta ofensiva social relevante en las mayores concentraciones urbanas donde se aproximan a una cuarta parte del electorado. Este éxito urbano debe verse conectado con la pervivencia más o menos transformada de un bloque social franquista que afectaría a sectores de clases medias políticamen-
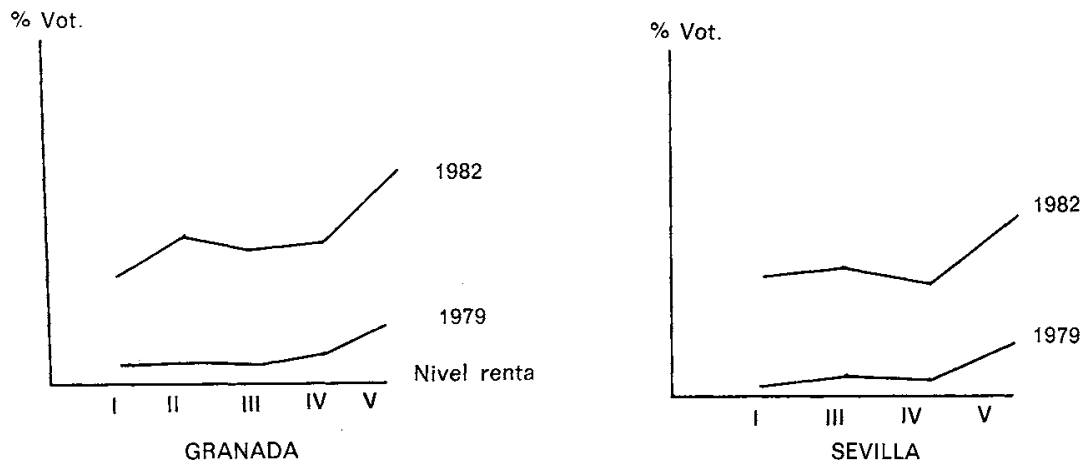

Curvas típicas de AP/CD.

Por niveles de renta. 
te bien definidas, que constituyen probablemente la base estable originaria del voto AP, cifrable en términos aproximados en un 5 por 100 del electorado.

El incremento restante en 1982 hasta superar el 20 por 100 en los mejores espacios debe alimentarse del voto burgués típico, anteriormente encuadrado en UCD, perfectamente coincidente con los mayores niveles de renta. Geográficamente es, pues, un voto urbano o de comarca de costa.

\section{RESULTADOS FINALES. EL UNIPARTIDISMO RESULTANTE DE 1982}

El resultado, tras las elecciones de 1982, presenta un panorama de claros tintes unipartidistas, con índice de Rae de representación parlamentaria por debajo del 0,50 , aunque sin cambios sustanciales en el diseño de las curvas estructurales de los partidos. La calificación exacta podría ser un cuasiunipartidismo polarizado, con un espectro:

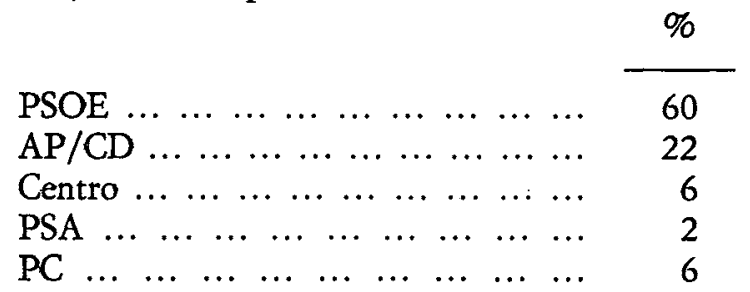

La reducción del pluralismo y su evolución se constata cronológicamente en la posición de los dos partidos mayoritarios:

$\%$

\begin{tabular}{|c|c|}
\hline & PSOE+UCD $\ldots \ldots \ldots \ldots$ \\
\hline 197 & PSOE +UCD $\ldots \ldots \ldots \ldots$ \\
\hline 1982 & 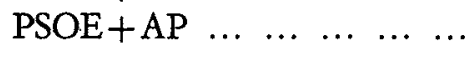 \\
\hline
\end{tabular}

Sin embargo, esta reducción cuasiunipartidista es el resultado del mayor dinamismo e intensidad en las traslaciones; un fenómeno que presenta más incidencia precisamente en las zonas caracterizadas por un mayor pluralismo interclasista, con electorado mayoritario de izquierda.

Así, se da la «paradoja» de que el espacio geográfico con mayor dinamicidad y pluralismo, el eje central de Córdoba-Sevilla, Cádiz-Málaga, es ahora el que presenta una mayor acumulación unipartidista, mientras las provincias con dinámica más conservadora y menor traslación de voto (Jaén, Granada, Almería) mantienen la anterior dispersión relativa, dando un pluralismo comparativamente más abierto, próximo al índice 0,6 de Rae. 
La paradoja se manifiesta también en el ámbito comarcal: ahora la mayor concentración del voto con menores índices de pluralismo se produce justamente en los espacios más flexibles de comportamiento, las capitales de provincia y la costa; detrás, con una ligera diferencia debido a la mayor estabilidad del voto comunista, aparece la campiña. $Y$ a la inversa, la máxima apertura pluralista se produce ahora jen la comarca de sierra!, justamente la caracterizada por una mayor petrificación y anquilosamiento de su dinámica electoral con escasa dimensión en los trasvases. Quizá otros factores como el nuevo electorado influyan en este proceso.

El sentido de este giro masivo de traslación, en beneficio del mayor partido de la izquierda, es el resultado de la interacción de a) una dinámica peculiar de centro «polarizado» — de Sartori-, la disolución del centro gubernamental, con b) una dinámica propia de bipartidismo: la fuerza centrípeta del partido alternativo; condicionada por las peculiaridades del proceso autonómico, dado el manifiesto carácter antigobierno central del voto andaluz al PSOE. La interacción es doble si se recuerda además que, en Andalucía, es el PSOE el que ocupa en rigor la posición «de centro», por representar la línea ideológica dominante, y con control del gobierno de la Junta, con oposiciones aunque parlamentariamente débiles e irresponsables, socialmente "fuertes» y con gran capacidad de «chantaje» político (especialmente el activo sindicalismo campesino): este centro PSOE ha debido beneficiarse obviamente de los impulsos hacia un proceso autonómico y un nacionalismo de carácter marcadamente reivindicativo: la posisión de alternativa gubernamental del PSOE venía a reforzar este proceso.

Sin embargo, cualitativamente, la curva o perfil estructural de cada partido ante las variables utilizadas apenas ha sufrido transformaciones constatables: han sido los sectores sociales con mayor dinamicidad pluralista los protagonistas de esta reversión unipartidista. La única incoherencia manifiesta en la comparación de los perfiles del 79 y el 82 viene a confirmar nuestra hipótesis: el mantenimiento de posiciones significativas de UCD en la sierra y zonas más pobres y periféricas, lo que demuestra la escasa elasticidad de este electorado. El PSOE sigue teniendo sus mejores posiciones (superiores al 60 por 100 ) en los sectores intermedios de renta y población, pero sus mayores avances relativos y absolutos se producen abora en los niveles mayores, incluyendo las capitales de provincia. El unipartidismo resultante no es, pues, consecuencia de un arcaísmo rural, sino de la máxima traslación del voto dinámico de los sectores socialmente más avanzados de Andalucía. 